\title{
Decomposition of the First-Order Reduced Density Matrix: An Isopycnic Localization Treatment
}

\author{
Diego R. Alcoba* and Roberto C. Bochicchio \\ Departamento de Física, Facultad de Ciencias Exactas y Naturales, Universidad de Buenos Aires, Ciudad \\ Universitaria, 1428, Buenos Aires, Argentina
}

\author{
Alicia Torre and Luis Lain \\ Departamento de Química Física, Facultad de Ciencias, Universidad del País Vasco, Apdo. 644, E-48080, \\ Bilbao, Spain
}

Received: January 27, 2006; In Final Form: May 24, 2006

\begin{abstract}
In this work, we propose a partitioning of the first-order reduced density matrix corresponding to an $N$-electron system into first-order reduced density matrices associated with regions defined in the real space (regional matrices). The treatment is based on an isopycnic orbital localization transformation that provides regional matrices that are diagonalized by identical localized orbitals, having many attributes associated with chemical concepts (appropriate localization in space, high transferability, etc.). Although the obtained numerical values are similar to those arising from previous studies, their interpretation is more rigorous and the computational cost is much lower.
\end{abstract}

\section{Introduction}

In previous studies on population analysis we have reported satisfactory results of chemical interest implementing partitionings of the first-order reduced density matrix of an $\mathrm{N}$-electron system in terms of correlated holes ${ }^{1}$ and first-order density matrices associated with Bader's regions. ${ }^{2}$ In both procedures, the extraction of the chemical information contained in these regional matrices has required two steps: (a) the partitioning of the first-order reduced density matrix into matrices associated with $M$ spatial regions and then (b) the performance of an isopycnic localization transformation of each one of the matrices arising from that partitioning. Although the numerical determinations obtained are in good agreement with the genuine chemical knowledge of the systems studied, in both treatments the results corresponding to each regional matrix have been obtained from a different localized orbital set and consequently these procedures do not provide a rigorous comparison between the results of each fragment.

The aim of this paper is to avoid this drawback by reporting a simpler treatment where only one isopycnic transformation is needed that provides all the results expressed in an identical basis set. This transformation is performed before the partitioning of the $N$-electron first-order reduced density matrix and consequently this treatment reverses the order in the performance of the two above-mentioned steps. This model, which represents a rigorous foundation for Cioslowski definitions of ionicity and bonding multiplicity by means of bond orders, ${ }^{3,4}$ provides regional matrices having many attributes usually associated with physical and chemical concepts (fulfillment of ensemble representability, ${ }^{5}$ appropriate localization in space, high transferability, etc.). All resulting regional matrices are diagonalized by identical localized orbitals and, consequently, the eigenvalues (electronic populations) of the density matrices corresponding to atomic spatial basins or those corresponding to unions of

* To whom correspondence should be addressed. Fax: ++54-1145763357. E-mail address: qfxaldad@lg.ehu.es. these basins (i.e., functional groups or any other arbitrary atomic associations) are strictly and straightforwardly comparable, which constitutes a significant accomplishment in a theoretical point of view. Apart from these achievements of theoretical nature, this treatment possesses another important advantage in a practical point of view: the computational cost is decreased by a factor of $M$ because only one localization transformation is carried out whereas $M$ localization ones are needed in previous treatments although the results turn out to be similar to those arising from former methods.

The article is organized as follows. The second section reports the main features of the isopycnic orbital localization transformations used in this work. The third section describes the decomposition of the usual first-order reduced density matrix into first-order matrices associated with Bader's atomic basins. This section also presents a study of the properties of these devices including their representability. The fourth section reports the computational aspects of this work, the results found in selected molecules, the corresponding discussion and a comparison between the present proposal and our previously described partitioning model. ${ }^{2}$ Finally, the last section summarizes the concluding remarks.

\section{Background of Isopycnic Orbital Localization Transformations}

Quantum-chemical calculations produce $N$-electron wave functions from which several quantities of interest can readily be derived. One of these quantities is the first-order reduced density matrix $\Gamma\left(x, x^{\prime}\right)$. This matrix, which uniquely determines expectation values of all one-electron operators, is usually described in terms of their natural spin-orbitals, $\psi_{i}(x)$, which are defined by the following equations:

$$
\Gamma\left(x, x^{\prime}\right)=\sum_{i} n_{i} \psi_{i}^{*}(x) \psi_{i}\left(x^{\prime}\right)
$$




$$
\begin{gathered}
\left\langle\psi_{i} \mid \psi_{i}\right\rangle=1 \\
\left\langle\psi_{i} \mid \psi_{j}\right\rangle=0 \quad i \neq j
\end{gathered}
$$

where $x$ and $x^{\prime}$ stand for the space and spin coordinates. The normalization condition, eq 2 , determines the values of the occupation numbers, $n_{i}$. There are, however, infinitely many sets of spin-orbitals, $\phi_{i}(x)$, and the corresponding occupation numbers, $v_{i}$, that satisfy eqs 1 and 2 , but not necessarily the orthogonality condition, eq 3 . Any linear transformation between the functions $\psi_{i}(x)$ and $\phi_{i}(x)$ leaves the first-order density matrix, rather than the wave function itself, invariant. Such a transformation, which has been termed as isopycnic, is defined by means of a matrix $C$ which satisfies ${ }^{6}$

$$
\begin{gathered}
\phi_{i}(x)=\sum_{j} C_{i j} \psi_{j}(x) \\
C_{i j}=U_{i j}\left(n_{j} / v_{i}\right)^{1 / 2}
\end{gathered}
$$

and

$$
v_{i}=\sum_{j} n_{j} U_{i j}^{*} U_{i j}
$$

where $U_{i j}$ are elements of a unitary matrix. This transformation, which preserves the diagonal form of $\Gamma\left(x, x^{\prime}\right)$ and yields real occupation numbers, $v_{i}$, satisfying the conditions

$$
\begin{aligned}
& 0 \leq v_{i} \leq 1 \\
& \sum_{i} v_{i}=N
\end{aligned}
$$

allows one to localize natural spin-orbitals that originate from arbitrary wave functions. Orbital localization is accomplished by finding an isopycnic orbital transformation matrix, $C$, that maximizes the localization index

$$
L=\sum_{i} \sum_{k l m n} v_{i}^{2} C_{i k}^{*} C_{i l} C_{i m}^{*} C_{i n} T_{k l m n}
$$

where the tensor $T_{k l m n}$ defines the localization procedure. Although several definitions for $T_{k l m n}$ are possible, ${ }^{7-13}$ in this paper we are interested in the Cioslowski localization criterion. ${ }^{14}$ In this case, the tensor $T$ is defined through the theory of atoms in molecules (AIM). ${ }^{15}$ As is well-known, this theory carries out a partitioning of the physical space based on the topological properties of the electron density function. The whole threedimensional space is divided into disjunct atomic basins $\Omega_{\mathrm{A}}$, which are defined by surfaces having zero flux in the gradient vector field of the electron density. Thus, within this procedure the tensor $T$ is defined so as to maximize an AIM charge-density overlap functional,

$$
T_{k l m n}=\sum_{\Omega_{\mathrm{A}}}\left\langle\psi_{k} \mid \psi_{l}\right\rangle_{\Omega_{\mathrm{A}}}\left\langle\psi_{m} \mid \psi_{n}\right\rangle_{\Omega_{\mathrm{A}}}
$$

in which $\left\langle\psi_{i} \mid \psi_{j}\right\rangle_{\Omega_{\mathrm{A}}}$ are the overlap integrals over the Bader atomic basins $\Omega_{\mathrm{A}}$ (where the integration is limited to this kind of basins). The quantity $\left\langle\psi_{i} \mid \psi_{i}\right\rangle_{\Omega_{\mathrm{A}}}$ defines the atomic population (occupancy) of the $i$ th spin-orbital on the atomic region $\Omega_{\mathrm{A}}$, and the quantity

$$
L_{i}=\sum_{\Omega_{\mathrm{A}}}\left\langle\psi_{i} \mid \psi_{i}\right\rangle_{\Omega_{\mathrm{A}}}\left\langle\psi_{i} \mid \psi_{i}\right\rangle_{\Omega_{\mathrm{A}}}
$$

is the localization index of the $i$ th spin-orbital and its inverse, $L_{i}^{-1}$, is equal to the effective number of atoms spanned by the $i$ th spin-orbital. ${ }^{14}$

Localized spin-orbitals resulting from this localization procedure do indeed have many attributes usually associated with chemical concepts (appropriate localization in space, high transferability, etc.) so that they can be regarded as the theoretical counterpart of the classical chemical pictures such as bonds, nonbonding electron pairs, core orbitals, valences and so forth, as has been shown in ref 4 . Therefore, the description of the first-order reduced density matrix in terms of these orbitals seems to be an adequate starting point to propose a partitioning of the first-order reduced density matrix corresponding to an $N$-electron system into first-order density matrices, each of them associated with an atomic basin defined in the AIM theory.

\section{Partitioning of the First-Order Reduced Density Matrix}

Let us consider the description of the first-order reduced density matrix in terms of its localized isopycnic-related natural spin-orbitals

$$
\Gamma\left(x, x^{\prime}\right)=\sum_{i} v_{i} \phi_{i}^{*}(x) \phi_{i}\left(x^{\prime}\right)
$$

Our philosophy is to combine these localized spin-orbitals according to their presence on the atomic basins in the molecule, to construct a set of first-order density matrices, each of them associated with an atomic basin defined in the AIM theory. Thus, let us consider the quantity $\left\langle\phi_{i} \mid \phi_{i}\right\rangle_{\Omega_{\mathrm{A}}}$ which, as mentioned above, defines the atomic population (occupancy) of the $i$ th localized spin-orbital on the atomic region $\Omega_{A}$. This quantity, which satisfies the relations

$$
\begin{gathered}
0 \leq\left\langle\phi_{i} \mid \phi_{i}\right\rangle_{\Omega_{\mathrm{A}}} \leq 1 \\
\sum_{\Omega_{\mathrm{A}}}\left\langle\phi_{i} \mid \phi_{i}\right\rangle_{\Omega_{\mathrm{A}}}=1
\end{gathered}
$$

yields a natural partitioning of the first-order reduced density matrix

$$
\Gamma\left(x, x^{\prime}\right)=\sum_{\Omega_{A}} \Gamma_{\Omega_{A}}\left(x, x^{\prime}\right)
$$

where

$$
\Gamma_{\Omega_{\mathrm{A}}}\left(x, x^{\prime}\right)=\sum_{i} v_{i}\left(\Omega_{\mathrm{A}}\right) \phi_{i}^{*}(x) \phi_{i}\left(x^{\prime}\right)
$$

and

$$
v_{i}\left(\Omega_{\mathrm{A}}\right)=v_{i}\left\langle\phi_{i} \mid \phi_{i}\right\rangle_{\Omega_{\mathrm{A}}}
$$

The matrices $\Gamma_{\Omega_{\mathrm{A}}}\left(x, x^{\prime}\right)$ constitute the first-order reduced density matrices associated with the regions $\Omega_{\mathrm{A}}$. From their definitions, eq 16, it follows that these matrices retain the chemical attributes of the localized orbitals from which they arise (appropriate localization in space, high transferability, etc.). Moreover, all of them diagonalize in the same isopycnic basis set, $\phi_{i}(x)$, and possess features similar to those of the ordinary reduced density matrix: each matrix is Hermitian and its trace is given by $N_{\Omega_{\mathrm{A}}}$, the number of electrons within the basin $\Omega_{\mathrm{A}}$, which coincides with Bader's (electronic) atomic charge as may be seen from 


$$
\begin{gathered}
\int \mathrm{d} x \Gamma_{\Omega_{\mathrm{A}}}(x, x)=\sum_{i} v_{i}\left(\Omega_{\mathrm{A}}\right)=\sum_{i} v_{i}\left\langle\phi_{i} \mid \phi_{i}\right\rangle_{\Omega_{\mathrm{A}}} \\
=\sum_{i k l}\left(n_{k} n_{l}\right)^{1 / 2} U_{i k}^{*} U_{i l}\left\langle\psi_{k} \mid \psi_{l}\right\rangle_{\Omega_{\mathrm{A}}} \\
=\sum_{k l}\left(n_{k} n_{l}\right)^{1 / 2} \delta_{k l}\left\langle\psi_{k} \mid \psi_{l}\right\rangle_{\Omega_{\mathrm{A}}}= \\
\sum_{k} n_{k}\left\langle\psi_{k} \mid \psi_{k}\right\rangle_{\Omega_{\mathrm{A}}}=N_{\Omega_{\mathrm{A}}} \text { (18) }
\end{gathered}
$$

where eqs 4-6 have been taken into account. The occupation numbers of the nonorthonormal localized natural spin-orbitals of $\Gamma_{\Omega_{\mathrm{A}}}\left(x, x^{\prime}\right), v_{i}\left(\Omega_{\mathrm{A}}\right)$, satisfy

$$
0 \leq v_{i}\left(\Omega_{\mathrm{A}}\right) \leq 1
$$

and, similarly, it follows that (see Appendix)

$$
0 \leq n_{i}\left(\Omega_{\mathrm{A}}\right) \leq 1
$$

where $n_{i}\left(\Omega_{\mathrm{A}}\right)$ are the occupation numbers of the orthonormal canonical natural spin-orbitals of $\Gamma_{\Omega_{\mathrm{A}}}\left(x, x^{\prime}\right)$, that is

$$
\Gamma_{\Omega_{\mathrm{A}}}\left(x, x^{\prime}\right)=\sum_{i} n_{i}\left(\Omega_{\mathrm{A}}\right) \tilde{\psi}_{i}^{*}(x) \tilde{\psi}_{i}\left(x^{\prime}\right)
$$

where

$$
n_{i}\left(\Omega_{\mathrm{A}}\right)=\sum_{j k}\left[v_{j}\left(\Omega_{\mathrm{A}}\right) v_{k}\left(\Omega_{\mathrm{A}}\right)\right]^{1 / 2} \tilde{U}_{j i}^{*} \tilde{U}_{k i}\left\langle\phi_{j} \mid \phi_{k}\right\rangle
$$

and $\tilde{\psi}_{i}(x)$, which in general differs from the original canonical one $\psi_{i}(x)$, is related to $\phi_{i}(x)$ through a new isopycnic orbital transformation

$$
\tilde{C}_{i j}=\tilde{U}_{i j}\left[n_{i}\left(\Omega_{\mathrm{A}}\right) / v_{j}\left(\Omega_{\mathrm{A}}\right)\right]^{1 / 2}
$$

where $\tilde{U}_{i j}$ are elements of a new unitary matrix. Finally, it must be noted that these regional matrices are defined after the localized orbitals have been determined. This fact provides that these matrices possess the important property of being independent of the orbital representation.

All these properties ensure the (ensemble) representability ${ }^{5}$ of the $\Gamma_{\Omega}\left(x, x^{\prime}\right)$ matrices and therefore their physical grounds and usefulness to describe first-order properties within the $\Omega$ regions. We must emphasize that the partitioning described in eq 15 leads to genuine first-order reduced density matrices associated with regions $\Omega$. In a previous study, ${ }^{2}$ we described a partitioning of the first-order reduced density matrix from a symmetrical expansion of the first-order reduced density matrix that preserves the essential properties of that matrix and also leads to true first-order reduced density matrices associated with regions $\Omega$. However, as has been pointed out in the Introduction, the former treatment required to perform a localization in each one of the regional matrices obtained and consequently the comparison of results is not rigorous. Moreover, that partitioning increases the computational expense because $M$ different localized basis sets need be constructed whereas only one is required in the present proposal. Both partitionings are distinct as a consequence of the different order in which localization and partitioning are performed in the present and the former model. These studies show that the partitioning of reduced density matrices allows different approaches that deserve to be considered in the description of atomic or functional groups.

\section{Computational Details, Results and Discussion}

In the previous sections we have expressed the first-order reduced density matrices in terms of spin-orbitals. However, for practical reasons the numerical determinations reported in this work have been performed through a spin-free formulation. As is well-known, the spin-free first-order reduced density matrix is given by

$$
\Gamma\left(r, r^{\prime}\right)=\sum_{\sigma} \Gamma\left(\{r, \sigma\},\left\{r^{\prime}, \sigma\right\}\right)
$$

where $\{r, \sigma\}$ stands for the set of spatial and spin coordinates, respectively. Analogously, the spin-free version of the $\Gamma_{\Omega}(\{r, \sigma\}$,$\left.\left\{r^{\prime}, \sigma\right\}\right)$ quantity will be defined as

$$
\Gamma_{\Omega}\left(r, r^{\prime}\right)=\sum_{\sigma} \Gamma_{\Omega}\left(\{r, \sigma\},\left\{r^{\prime}, \sigma\right\}\right)
$$

For states having spin quantum number $S_{z}=0$ (singlets and other states), the spin-free first-order reduced density matrix associated with the region $\Omega$ can be calculated straightforwardly starting with the matrix $\Gamma\left(r, r^{\prime}\right)$. This allow us to handle matrices of lesser size with lower computational expenses than those demanded by the spin-orbital formulation. The treatment of states with $S_{\mathrm{Z}} \neq 0$ requires the independent evaluation of the $\Gamma_{\Omega}\left(\{r, \alpha\},\left\{r^{\prime}, \alpha\right\}\right)$ and $\Gamma_{\Omega}\left(\{r, \beta\},\left\{r^{\prime}, \beta\right\}\right)$ matrices, because $\Gamma_{\Omega^{-}}$ $\left(\{r, \alpha\},\left\{r^{\prime}, \alpha\right\}\right) \neq \Gamma_{\Omega}\left(\{r, \beta\},\left\{r^{\prime}, \beta\right\}\right),{ }^{16,17}$ and then, in a subsequent step, to add both spin blocks according to eq 25 .

The $\Gamma_{\Omega}\left(r, r^{\prime}\right)$ matrices can be extended to unions between basins $\cup_{\mathrm{A}} \Omega_{\mathrm{A}}$, that is,

$$
\Gamma_{\left(\cup_{\mathrm{A}} \Omega_{\mathrm{A}}\right)}\left(r, r^{\prime}\right)=\sum_{i} v_{i}\left(\cup_{\mathrm{A}} \Omega_{\mathrm{A}}\right) \phi_{i}^{*}(r) \phi_{i}\left(r^{\prime}\right)
$$

where

$$
v_{i}\left(\cup_{\mathrm{A}} \Omega_{\mathrm{A}}\right)=\sum_{\Omega_{\mathrm{A}}}^{\prime} v_{i}\left\langle\phi_{i} \mid \phi_{i}\right\rangle_{\Omega_{\mathrm{A}}}
$$

and the sum $\sum^{\prime} \Omega_{\mathrm{A}}$ is restricted to the $\Omega_{\mathrm{A}}$ regions that are included in the union set $\cup_{\mathrm{A}} \Omega_{\mathrm{A}}$. Obviously, if $\cup_{\mathrm{A}} \Omega_{\mathrm{A}}$ is the whole space $\Gamma_{\left(\cup_{A} \Omega_{A}\right)}\left(r, r^{\prime}\right)=\Gamma\left(r, r^{\prime}\right)$ and $N_{\left(\cup_{A} \Omega_{A}\right)}=N$. These properties guarantee that the $\Gamma_{\Omega}\left(r, r^{\prime}\right)$ matrices are appropriate tools to describe molecular fragments of chemical interest, like atoms, functional groups, etc. Such a description allows one to analyze electronic populations and their degeneracies in terms of inner shells, lone pairs, inner bondings within a determined region $\Omega$ as well as bondings of that region with the rest of the molecule.

To test the usefulness of the above proposed partitioning of first-order reduced density matrix, we have chosen the series of hydrides of the second-row elements, some diatomic molecules and simple hydrocarbons, all of them in the singlet ground states so that the spin-free formulation can be used. The calculations were carried out using Gaussian $03^{18}$ program, which generated the first-order reduced density matrix elements and the overlap matrices $\left\langle\psi_{i} \mid \psi_{j}\right\rangle_{\Omega_{\mathrm{A}}}$. In a subsequent step, these matrices were subjected to our own computational implementation. The results reported for those systems have been obtained with the basis sets 6-31G(d,p) except for the acetylene molecule which has been calculated with the 6-31G basis set to avoid the occurrence of the nonnuclear attractor, which appears with the former set. ${ }^{19,20}$ A study of the basis set dependency of this methodology has also been performed using several basis sets on the HF molecule, chosen as test example. For all systems, the geometries were optimized for the corresponding basis sets within configuration interaction (CI) wave functions with single and double excitations (SDCI) arising from Hartree-Fock reference states. 
TABLE 1: Calculated Eigenvalues $v_{i}(\Omega)$ (Electronic Populations) and Assigned Eigenvectors of Localization Based First-Order Reduced Density Matrices Associated with Bader's Regions, Ionicities of Bonds (as a Percentage) and Covalent Bond Orders for Second-Row Hydrides in the SDCI Treatment Using the 6-31G $(d, p)$ Basis Set

\begin{tabular}{|c|c|c|c|c|c|c|c|c|}
\hline system & fragment $(\Omega)$ & $N_{\Omega}$ & $v_{i}(\Omega)$ & degeneracy & assignment & ionicity & bond & covalent bond order \\
\hline \multirow[t]{6}{*}{$\mathrm{BeH}_{2}$} & $\mathrm{Be}$ & 2.277 & 1.991 & 1 & $1 \mathrm{~s}_{\mathrm{Be}}$ & & $\mathrm{Be}-\mathrm{H}$ & 0.261 \\
\hline & & & 0.138 & 2 & $\sigma_{\mathrm{BeH}}$ & 85.8 & & \\
\hline & $\mathrm{H}$ & 1.862 & 1.804 & 1 & $\sigma_{\mathrm{BeH}}$ & 85.8 & $\mathrm{H}-\mathrm{H}$ & 0.088 \\
\hline & $\mathrm{BeH}$ & 4.138 & 1.995 & 1 & $1 \mathrm{~s}_{\mathrm{Be}}$ & & & \\
\hline & & & 1.942 & 1 & $\sigma_{\mathrm{BeH}}($ inner $\mathrm{H})$ & & & \\
\hline & & & 0.162 & 1 & $\sigma_{\mathrm{BeH}}($ outer $\mathrm{H})$ & & & \\
\hline \multirow[t]{6}{*}{$\mathrm{BH}_{3}$} & B & 2.946 & 1.997 & 1 & $1 \mathrm{~s}_{\mathrm{B}}$ & & $\mathrm{B}-\mathrm{H}$ & 0.512 \\
\hline & & & 0.307 & 3 & $\sigma_{\mathrm{BH}}$ & 67.4 & & \\
\hline & $\mathrm{H}$ & 1.685 & 1.576 & 1 & $\sigma_{\mathrm{BH}}$ & 67.4 & $\mathrm{H}-\mathrm{H}$ & 0.136 \\
\hline & $\mathrm{BH}$ & 4.631 & 1.998 & 1 & $1 \mathrm{~s}_{\mathrm{B}}$ & & & \\
\hline & & & 1.883 & 1 & $\sigma_{\mathrm{BH}}($ inner $\mathrm{H})$ & & & \\
\hline & & & 0.349 & 2 & $\sigma_{\mathrm{BH}}($ outer $\mathrm{H})$ & & & \\
\hline \multirow[t]{6}{*}{$\mathrm{CH}_{4}$} & $\mathrm{C}$ & 5.845 & 2.000 & 1 & $1 \mathrm{~s}_{\mathrm{C}}$ & & $\mathrm{C}-\mathrm{H}$ & 0.970 \\
\hline & & & 0.947 & 4 & $\sigma_{\mathrm{CH}}$ & 1.1 & & \\
\hline & $\mathrm{H}$ & 1.039 & 0.967 & 1 & $\sigma_{\mathrm{CH}}$ & 1.1 & $\mathrm{H}-\mathrm{H}$ & 0.038 \\
\hline & $\mathrm{CH}$ & 6.884 & 2.000 & 1 & $1 \mathrm{~s}_{\mathrm{C}}$ & & & \\
\hline & & & 1.914 & 1 & $\sigma_{\mathrm{CH}}($ inner $\mathrm{H})$ & & & \\
\hline & & & 0.966 & 3 & $\sigma_{\mathrm{CH}}($ outer $\mathrm{H})$ & & & \\
\hline \multirow[t]{8}{*}{$\mathrm{NH}_{3}$} & $\mathrm{~N}$ & 8.010 & 2.000 & 1 & $1 \mathrm{~s}_{\mathrm{N}}$ & & $\mathrm{N}-\mathrm{H}$ & 0.875 \\
\hline & & & 1.929 & 1 & lone pair & & & \\
\hline & & & 1.339 & 3 & $\sigma_{\mathrm{NH}}$ & 37.7 & & \\
\hline & $\mathrm{H}$ & 0.663 & 0.606 & 1 & $\sigma_{\mathrm{NH}}$ & 37.7 & $\mathrm{H}-\mathrm{H}$ & 0.015 \\
\hline & $\mathrm{NH}$ & 8.674 & 2.000 & 1 & $1 \mathrm{~s}_{\mathrm{N}}$ & & & \\
\hline & & & 1.944 & 1 & lone pair & & & \\
\hline & & & 1.945 & 1 & $\sigma_{\mathrm{NH}}($ inner $\mathrm{H})$ & & & \\
\hline & & & 1.351 & 2 & $\sigma_{\mathrm{NH}}($ outer $\mathrm{H})$ & & & \\
\hline \multirow[t]{9}{*}{$\mathrm{H}_{2} \mathrm{O}$} & $\mathrm{O}$ & 9.148 & 2.000 & 1 & $1 \mathrm{~s}_{\mathrm{O}}$ & & $\mathrm{O}-\mathrm{H}$ & 0.655 \\
\hline & & & 1.974 & 1 & $\sigma$-lone pair & & & \\
\hline & & & 1.953 & 1 & $\pi$-lone pair & & & \\
\hline & & & 1.573 & 2 & $\sigma_{\mathrm{OH}}$ & 60.4 & & \\
\hline & $\mathrm{H}$ & 0.426 & 0.389 & 1 & $\sigma_{\mathrm{OH}}$ & 60.4 & $\mathrm{H}-\mathrm{H}$ & 0.006 \\
\hline & $\mathrm{OH}$ & 9.574 & 2.000 & 1 & $1 \mathrm{so}_{\mathrm{O}}$ & & & \\
\hline & & & 1.963 & 2 & $\sigma$-lone pair; & & & \\
\hline & & & 1.979 & 1 & $\pi$-lone pair & & & \\
\hline & & & 1.581 & 1 & $\sigma_{\mathrm{OH}}($ outer $\mathrm{H})$ & & & \\
\hline \multirow[t]{5}{*}{$\mathrm{HF}$} & $F$ & 9.711 & 2.000 & 1 & $1 \mathrm{~s}_{\mathrm{F}}$ & & $\mathrm{F}-\mathrm{H}$ & 0.479 \\
\hline & & & 1.988 & 1 & $\sigma$-lone pair & & & \\
\hline & & & 1.975 & 2 & $\pi$-lone pair & & & \\
\hline & & & 1.706 & 1 & $\sigma_{\mathrm{FH}}$ & 73.0 & & \\
\hline & $H$ & 0.289 & 0.266 & 1 & $\sigma_{\mathrm{FH}}$ & 73.0 & & \\
\hline
\end{tabular}

The results in Table 1 show the values $N_{\Omega}$ found in the monatomic and diatomic fragments that can be outlined in the series of hydrides of the second-row elements. This table also reports the partitioning $N_{\Omega}=\sum_{i} v_{i}(\Omega)$ in terms of the nonnegligible $v_{i}(\Omega)$ values (see eq 18 ) as well as the degeneracy of the corresponding localized orbitals. These quantities allow us to carry out a suitable assignment of these orbitals in good agreement with the genuine chemical knowledge, as is shown in column six. The $v_{i}(\Omega)$ values point out the polarity of the bonding of the region $\Omega$ with other regions; e.g., the diatomic fragments $\mathrm{A}-\mathrm{H}(\mathrm{A}=\mathrm{Be}, \mathrm{B}, \mathrm{C}, \mathrm{N}, \mathrm{O}, \mathrm{F})$ fulfill $v_{i}(\mathrm{H})>v_{i}(\mathrm{~A})$ in the systems $\mathrm{BeH}_{2}(1.804>0.138)$ and $\mathrm{BH}_{3}(1.576>0.307)$, showing the negative character of the $\mathrm{H}$ basins but $v_{i}(\mathrm{H})<v_{i^{-}}$ (A), as expected, in the compounds $\mathrm{NH}_{3}(0.606<1.339), \mathrm{H}_{2} \mathrm{O}$ $(0.389<1.573)$ and $\mathrm{HF}(0.266<1.706)$. A quantitative measure of this polarity has been written down in column seven of this table, which reports the ionicity (as a percentage) of the bondings $\mathrm{A}-\mathrm{H}$. The ionicity of these bondings has been evaluated in terms of the values $v_{i}(\mathrm{~A})$ and $v_{i}(\mathrm{H})$ corresponding to the localized orbitals $\phi_{i}(r)$ which describes that bonding as ${ }^{2}$

$$
\left|\frac{v_{i}(\mathrm{~A})-v_{i}(\mathrm{H})}{v_{i}(\mathrm{~A})+v_{i}(\mathrm{H})}\right|
$$

which is identical to the ionicity index of the bondings $\mathrm{A}-\mathrm{H}$ arising from the more conventional method reported by Cioslowski and Mixon ${ }^{3}$

$$
\left|\frac{\left\langle\phi_{i} \mid \phi_{i}\right\rangle_{\mathrm{A}}-\left\langle\phi_{i} \mid \phi_{i}\right\rangle_{\mathrm{H}}}{\left\langle\phi_{i} \mid \phi_{i}\right\rangle_{\mathrm{A}}+\left\langle\phi_{i} \mid \phi_{i}\right\rangle_{\mathrm{H}}}\right|
$$

In the last column of Table 1 we report a covalent bond order derived from this framework. This quantity, which is consistent with the exchange definition derived in ref 21 , allows one to assess the index of bonding between two atoms $\mathrm{A}$ and $\mathrm{B}$ according to the Lewis (resonance) structure described by the particular set of localized orbitals $\phi_{i}(r)$. This quantity can be calculated directly knowing the electronic populations associated with $\Gamma_{\Omega}\left(r, r^{\prime}\right)$ matrices as

$$
P_{\mathrm{AB}}=\sum_{i} v_{i}(\mathrm{~A}) v_{i}(\mathrm{~B})
$$

A comparison of our definition with that reported in ref 4

$$
P_{\mathrm{AB}}=\sum_{i} v_{i}^{2}\left\langle\phi_{i} \mid \phi_{i}\right\rangle_{\mathrm{A}}\left\langle\phi_{i} \mid \phi_{i}\right\rangle_{\mathrm{B}}
$$

shows that both quantities are coincident. These results confirm, as has been pointed out in the Introduction, that the ionicity 
TABLE 2: Calculated Eigenvalues $v_{i}(\boldsymbol{\Omega})$ (Electronic Populations) and Assigned Eigenvectors of Localization Based First-order Reduced Density Matrices Associated with Bader's Regions, Ionicities of Bonds (as a Percentage) and Covalent Bond Orders for Diatomic Molecules and Hydrocarbons in the SDCI Treatment Using the 6-31G(d,p) Basis Set

\begin{tabular}{|c|c|c|c|c|c|c|c|c|}
\hline system & fragment $(\Omega)$ & $N_{\Omega}$ & $v_{i}(\Omega)$ & degeneracy & assignment & ionicity & bond & covalent bond order \\
\hline \multirow[t]{4}{*}{$\mathrm{N}_{2}$} & $\mathrm{~N}$ & 7.000 & 2.000 & 1 & $1 \mathrm{~s}_{\mathrm{N}}$ & & $\mathrm{N}-\mathrm{N}$ & 2.913 \\
\hline & & & 1.966 & 1 & $\sigma$-lone pair & & & \\
\hline & & & 0.989 & 1 & $\sigma_{\mathrm{NN}^{\prime}}$ & & & \\
\hline & & & 0.974 & 2 & $\pi_{\mathrm{NN}^{\prime}}$ & & & \\
\hline \multirow[t]{8}{*}{$\mathrm{CO}$} & $\mathrm{C}$ & 4.738 & 1.996 & 1 & $1 \mathrm{~s}_{\mathrm{C}}$ & & $\mathrm{C}-\mathrm{O}$ & 1.558 \\
\hline & & & 1.856 & 1 & $\sigma$-lone pair & & & \\
\hline & & & 0.224 & 1 & $\sigma_{\mathrm{CO}}$ & 77.4 & & \\
\hline & & & 0.288 & 2 & $\pi_{\mathrm{CO}}$ & 70.5 & & \\
\hline & $\mathrm{O}$ & 9.262 & 2.000 & 1 & $1 \mathrm{~s}_{\mathrm{O}}$ & & & \\
\hline & & & 1.983 & 1 & $\sigma$-lone pair & & & \\
\hline & & & 1.754 & 1 & $\sigma_{\mathrm{CO}}$ & 77.4 & & \\
\hline & & & 1.666 & 2 & $\pi_{\mathrm{CO}}$ & 70.5 & & \\
\hline \multirow[t]{4}{*}{$\mathrm{F}_{2}$} & $\mathrm{~F}$ & 9.000 & 2.000 & 1 & $1 \mathrm{~s}_{\mathrm{F}}$ & & $\mathrm{F}-\mathrm{F}$ & 1.180 \\
\hline & & & 1.978 & 1 & $\sigma$-lone pair & & & \\
\hline & & & 1.956 & 2 & $\pi$-lone pair & & & \\
\hline & & & 0.964 & 1 & $\sigma_{\mathrm{FF}^{\prime}}$ & & & \\
\hline \multirow{10}{*}{$\begin{array}{l}\mathrm{C}_{2} \mathrm{H}_{6}\left(\mathrm{D}_{3 \mathrm{~h}}\right) \\
\left(\mathrm{H}_{3} \mathrm{C}-\mathrm{C}^{\prime} \mathrm{H}_{3}{ }^{\prime}\right)\end{array}$} & $\mathrm{C}$ & 5.838 & 2.000 & 1 & $1 \mathrm{~s}_{\mathrm{C}}$ & & $\mathrm{C}-\mathrm{C}$ & 0.985 \\
\hline & & & 0.936 & 1 & $\sigma_{\mathrm{CC}^{\prime}}$ & & $\mathrm{C}-\mathrm{H}$ & 0.963 \\
\hline & & & 0.930 & 3 & $\sigma_{\mathrm{CH}}$ & 2.6 & & \\
\hline & $\mathrm{H}$ & 1.054 & 0.979 & 1 & $\sigma_{\mathrm{CH}}$ & 2.6 & $\mathrm{H}-\mathrm{H}$ & 0.040 \\
\hline & $\mathrm{CC}^{\prime}$ & 11.675 & 2.000 & 2 & $1 \mathrm{~s}_{\mathrm{C}} ; 1 \mathrm{~s}_{\mathrm{C}^{\prime}}$ & & & \\
\hline & & & 1.872 & 1 & $\sigma_{\mathrm{CC}^{\prime}}$ & & & \\
\hline & & & 0.949 & 6 & $\sigma_{\mathrm{CH}} ; \sigma_{\mathrm{C}^{\prime} \mathrm{H}^{\prime}}$ & & & \\
\hline & $\mathrm{CH}_{3}$ & 9.000 & 2.000 & 1 & $1 \mathrm{~s}_{\mathrm{C}}$ & & & \\
\hline & & & 1.949 & 3 & $\sigma_{\mathrm{CH}}$ & & & \\
\hline & & & 0.985 & 1 & $\sigma_{\mathrm{CC}^{\prime}}$ & & & \\
\hline \multirow{13}{*}{$\begin{array}{l}\mathrm{C}_{2} \mathrm{H}_{4} \\
\left(\mathrm{H}_{2} \mathrm{C}-\mathrm{C}^{\prime} \mathrm{H}_{2}{ }^{\prime}\right)\end{array}$} & $\mathrm{C}$ & 5.953 & 2.000 & 1 & $1 \mathrm{~s}_{\mathrm{C}}$ & & $\mathrm{C}-\mathrm{C}$ & 1.857 \\
\hline & & & 0.981 & 2 & $\sigma_{\mathrm{CH}}$ & 1.6 & $\mathrm{C}-\mathrm{H}$ & 0.984 \\
\hline & & & 0.965 & 1 & $\sigma_{\mathrm{CC}^{\prime}}$ & & & \\
\hline & & & 0.917 & 1 & $\pi_{\mathrm{CC}^{\prime}}$ & & & \\
\hline & $\mathrm{H}$ & 1.024 & 0.951 & 1 & $\sigma_{\mathrm{CH}}$ & 1.6 & $\mathrm{H}-\mathrm{H}$ & 0.031 \\
\hline & $\mathrm{CC}^{\prime}$ & 11.901 & 2.000 & 2 & $1 \mathrm{~s}_{\mathrm{C}} ; 1 \mathrm{~s}_{\mathrm{C}^{\prime}}$ & & & \\
\hline & & & 1.929 & 1 & $\sigma_{\mathrm{CC}^{\prime}}$ & & & \\
\hline & & & 1.835 & 1 & $\pi_{\mathrm{CC}^{\prime}}$ & & & \\
\hline & & & 1.002 & 4 & $\sigma_{\mathrm{CH}} ; \sigma_{\mathrm{C}^{\prime} \mathrm{H}^{\prime}}$ & & & \\
\hline & $\mathrm{CH}_{2}$ & 8.000 & 2.000 & 1 & $1 \mathrm{~s}_{\mathrm{C}}$ & & & \\
\hline & & & 1.947 & 2 & $\sigma_{\mathrm{CH}}$ & & & \\
\hline & & & 0.987 & 1 & $\sigma_{\mathrm{CC}^{\prime}}$ & & & \\
\hline & & & 0.971 & 1 & $\pi_{\mathrm{CC}^{\prime}}$ & & & \\
\hline $\mathrm{C}_{2} \mathrm{H}_{2}{ }^{a}$ & $\mathrm{C}$ & 6.137 & 2.000 & 1 & $1 \mathrm{~s}_{\mathrm{C}}$ & & $\mathrm{C}-\mathrm{C}$ & 2.785 \\
\hline \multirow[t]{12}{*}{$\left(\mathrm{HC}-\mathrm{C}^{\prime} \mathrm{H}^{\prime}\right)$} & & & 1.175 & 1 & $\sigma_{\mathrm{CH}}$ & 19.2 & $\mathrm{C}-\mathrm{H}$ & 0.986 \\
\hline & & & 0.972 & 1 & $\sigma_{\mathrm{CC}^{\prime}}$ & & & \\
\hline & & & 0.955 & 2 & $\pi_{\mathrm{CC}^{\prime}}$ & & & \\
\hline & $\mathrm{H}$ & 0.863 & 0.797 & 1 & $\sigma_{\mathrm{CH}}$ & 19.2 & $\mathrm{H}-\mathrm{H}$ & 0.001 \\
\hline & $\mathrm{CC}^{\prime}$ & 12.274 & 2.000 & 2 & $1 \mathrm{~s}_{\mathrm{C}} ; 1 \mathrm{~s}_{\mathrm{C}^{\prime}}$ & & & \\
\hline & & & 1.945 & 1 & $\sigma_{\mathrm{CC}^{\prime}}$ & & & \\
\hline & & & 1.910 & 2 & $\pi_{\mathrm{CC}^{\prime}}$ & & & \\
\hline & & & 1.181 & 2 & $\sigma_{\mathrm{CH}} ; \sigma_{\mathrm{C}^{\prime} \mathrm{H}^{\prime}}$ & & & \\
\hline & $\mathrm{CH}$ & 7.000 & 2.000 & 1 & $1 \mathrm{~s}_{\mathrm{C}}$ & & & \\
\hline & & & 1.972 & 1 & $\sigma_{\mathrm{CH}}$ & & & \\
\hline & & & 0.991 & 1 & $\sigma_{\mathrm{CC}^{\prime}}$ & & & \\
\hline & & & 0.972 & 2 & $\pi_{\mathrm{CC}^{\prime}}$ & & & \\
\hline
\end{tabular}

${ }^{a}$ Calculated in the 6-31G basis set.

index and the bond order can be derived suitably from our methodology of regional reduced density matrices.

In Table 2 we report identical quantities to those mentioned in the previous one, describing atoms contained in diatomic (homonuclear and heteronuclear) molecules and fragments of chemical interest in the simplest hydrocarbons possessing single, double and triple bond orders. A survey of the values found shows that the degeneracies and assignments are in excellent agreement with the expected features for these molecules. The polarity of the bondings in homonuclear molecules $\left(\mathrm{N}_{2}\right.$ and $\left.\mathrm{F}_{2}\right)$ is zero whereas the $\mathrm{CO}$ molecule presents reasonable values for both $\sigma_{\mathrm{CO}}$ and $\pi_{\mathrm{CO}}$ bonds. Similar comments deserve the bond orders found for all systems as in the diatomic molecules as in the hydrocarbons (single, double and triple bondings $\mathrm{C}-\mathrm{C}$ and $\mathrm{C}-\mathrm{H}$ ). The method predicts very low values for the polarity of the bondings $\mathrm{C}-\mathrm{H}$ in the $\mathrm{C}_{2} \mathrm{H}_{6}$ and $\mathrm{C}_{2} \mathrm{H}_{4}$ molecules and a higher one for the $\mathrm{C}_{2} \mathrm{H}_{2}$ system in which the $\mathrm{H}$ fragment has a positive charge in good agreement with the well-known properties of this hydrocarbon.

Table 3 shows the values of ionicity and covalent bond order obtained for the HF molecule within this methodology using several basis sets. Starting with a minimal STO-3G basis set, the increase of the basis set size initially provides an increase of the ionicity and the corresponding decrease of the covalent bond order, and this effect in reinforced when polarization functions are included. However, as can be observed in the table, once the basis set size is sufficiently large, further size increases do not provide substantial changes in the reported quantities. These results allow us to infer the stability of the ionicity and bond order values once the basis set is large enough. 
TABLE 3: Basis Set Dependence of Ionicities of Bonds (as a Percentage) and Covalent Bond Orders for the HF Molecule in the SDCI Treatment

\begin{tabular}{|c|c|c|c|c|c|}
\hline basis set & dimension & $N_{\Omega \mathrm{F}}$ & $N_{\Omega \mathrm{H}}$ & ionicity & $\begin{array}{c}\text { covalent } \\
\text { bond order }\end{array}$ \\
\hline STO-3G & 6 & 9.372 & 0.627 & 40.2 & 0.825 \\
\hline $3-21 \mathrm{G}$ & 11 & 9.539 & 0.461 & 56.4 & 0.694 \\
\hline $6-31 \mathrm{G}$ & 11 & 9.592 & 0.408 & 61.6 & 0.632 \\
\hline D95V & 11 & 9.601 & 0.399 & 62.8 & 0.619 \\
\hline $6-31 G(d)$ & 17 & 9.684 & 0.316 & 70.1 & 0.513 \\
\hline cc-pVDZ & 19 & 9.723 & 0.277 & 74.4 & 0.462 \\
\hline $6-31 \mathrm{G}(\mathrm{d}, \mathrm{p})$ & 20 & 9.711 & 0.289 & 73.0 & 0.479 \\
\hline D95V(d,p) & 20 & 9.715 & 0.285 & 73.7 & 0.427 \\
\hline $6-31+\mathrm{G}(\mathrm{d}, \mathrm{p})$ & 24 & 9.723 & 0.277 & 74.4 & 0.462 \\
\hline $6-31 G(2 d, 2 p)$ & 29 & 9.714 & 0.286 & 73.6 & 0.475 \\
\hline cc-pVTZ ${ }^{a}$ & 44 & 9.745 & 0.255 & 76.4 & 0.433 \\
\hline
\end{tabular}

${ }^{a}$ The $\left\langle\psi_{i} \mid \psi_{j}\right\rangle_{\Omega_{A}}$ integrals were obtained from Proaim program ${ }^{22}$ for this basis set.

In ref 2 we described a model that performs a topological partitioning of the first-order reduced density matrix according to an algebraic symmetrical expansion of that matrix, i.e.

$$
\Gamma\left(r, r^{\prime}\right)=\sum_{\Omega_{\mathrm{A}}} \Gamma_{\Omega_{\mathrm{A}}}^{\prime}\left(r, r^{\prime}\right)
$$

where

$$
\Gamma_{\Omega_{\mathrm{A}}}^{\prime}\left(r, r^{\prime}\right)=\sum_{i j}\left(n_{i} n_{j}\right)^{1 / 2}\left\langle\psi_{i} \mid \psi_{j}\right\rangle_{\Omega_{\mathrm{A}}} \psi_{i}^{*}(r) \psi_{j}\left(r^{\prime}\right)
$$

This model deals with the natural orbitals $\psi_{i}(r)$ and their corresponding occupation numbers $n_{i}$. The extraction of the chemical information contained in these regional matrices requires the performance of an isopycnic localization transformation of each one of the matrices whereas in the present model the resulting regional first-order reduced density matrices diagonalize in the same localized basis set. This property renders a direct and strictly valid comparison between atomic populations and localized orbitals corresponding to different regional matrices arising from the present model. The systems described in Tables 1 and 2 were also calculated in ref 2 within the symmetrical model. The results turn out to be similar to those arising from the present scheme, although the former one is computationally much more expensive. It is also interesting to highlight that the ionicities index of a bond are almost identical in both models.

Let us finish this section by pointing out that alternative descriptions of some of the systems studied in the present work can be derived from approaches others than AIM one. Thus, for example, in the valence bond theory (VB) the bond in the $\mathrm{F}_{2}$ molecule is interpreted in terms of a charge-shift bond in which the resonance of the ionic structures is the stabilizing contribution; this feature, which is not discriminated by the AIM scheme, is supported by the electron localization function (ELF) approach. $^{23}$

\section{Concluding Remarks}

In conclusion, in this paper we report a procedure to decompose the first-order reduced density matrix of an $\mathrm{N}$ electron system into regional first-order reduced density matrices according to the three-dimensional atomic basins defined in the AIM theory. The first step in this procedure involves one isopycnic localization transformation, which provides that the regional matrices resulting from the subsequent partitioning are diagonalized by identical localized orbitals. We have performed a study of the representability conditions for these regional matrices whose fulfillment ensures the physical grounds and the reliability of the information arising from these devices. We have also described first-order reduced density matrices associated with unions of atomic basins, whose treatment provides an important chemical information which has been related with groups of atoms. The results obtained within this scheme have allowed us to describe satisfactorily molecular fragments and their bondings with a lower computational cost than previously reported models. Moreover, our treatment evaluates the polarity, ionicity and bonding multiplicity from the information contained in the regional matrices leading to identical values than those predicted by more conventional methods. The good agreement between our results and those arising from the genuine chemical knowledge shows that this methodology is a useful and cost competitive tool for the understanding and description of molecular structures. We are currently working on the application of this methodology to determine functional groups in several series of organic compounds.

Acknowledgment. D.R.A. and R.C.B. acknowledge grants in aid from the Universidad de Buenos Aires (Project No. $\mathrm{X}-024)$ and the Consejo Nacional de Investigaciones Científicas y Ténicas, República Argentina (PIP No. 5098/05), and the Department of Physics, Facultad de Ciencias Exactas y Naturales, Universidad de Buenos Aires, for facilities provided during the course of this work. This work was partly supported by the Spanish Ministry of Education (Grant No. BQU2003-00359) and the Universidad del Pais Vasco (Grant No. 00039.31015261/2003). We also thank the Universidad del Pais Vasco for allocation of computational resources.

\section{Appendix}

Let us consider the expression that relates the $\Omega_{A}$ basin canonical natural occupation numbers with those corresponding to localized orbitals

$$
n_{i}\left(\Omega_{\mathrm{A}}\right)=\sum_{j k}\left[v_{j}\left(\Omega_{\mathrm{A}}\right) v_{k}\left(\Omega_{\mathrm{A}}\right)\right]^{1 / 2} \tilde{U}_{j i}^{*} \tilde{U}_{k i}\left\langle\phi_{j} \mid \phi_{k}\right\rangle
$$

Defining

$$
\left|\tau_{i}\right\rangle=\sum_{k}\left[v_{k}\left(\Omega_{\mathrm{A}}\right)\right]^{1 / 2} \tilde{U}_{k i}\left|\phi_{k}\right\rangle
$$

it follows that

$$
n_{i}\left(\Omega_{\mathrm{A}}\right)=\left\langle\tau_{i} \mid \tau_{i}\right\rangle
$$

and therefore

$$
n_{i}\left(\Omega_{\mathrm{A}}\right) \geq 0
$$




$$
\begin{aligned}
& n_{i}\left(\Omega_{\mathrm{A}}\right)=\sum_{j k}\left[v_{j}\left(\Omega_{\mathrm{A}}\right) v_{k}\left(\Omega_{\mathrm{A}}\right)\right]^{1 / 2} \tilde{U}_{j i}^{*} \tilde{U}_{k i}\left\langle\phi_{j} \mid \phi_{k}\right\rangle \\
&=\sum_{j k} \sum_{p q}\left[v_{j}\left(\Omega_{\mathrm{A}}\right) v_{k}\left(\Omega_{\mathrm{A}}\right)\right]^{1 / 2} \tilde{U}_{j i}^{*} \tilde{U}_{k i}\left(n_{p} n_{q}\right)^{1 / 2}\left(v_{j} v_{k}\right)^{-1 / 2} \times \\
&=\sum_{j k} \sum_{p}\left(\left\langle\phi_{j} \mid \phi_{j}\right\rangle_{\Omega_{\mathrm{A}}}\left\langle\phi_{k} \mid \phi_{p}\right\rangle_{\Omega_{\mathrm{A}}}\right)^{1 / 2} \tilde{U}_{j i}^{*} \tilde{U}_{k i} U_{j p}^{*} U_{k p} n_{p} \\
&=\sum_{p}\left[\sum_{j}\left(\left\langle\phi_{j} \mid \phi_{j}\right\rangle_{\Omega_{\mathrm{A}}}\right)^{1 / 2} \tilde{U}_{j i}^{*} U_{j p}^{*}\right] \times \\
& {\left[\sum_{k} \tilde{U}_{k i}^{*} U_{k p}^{*}\left(\left\langle\phi_{k} \mid \phi_{k}\right\rangle_{\Omega_{\mathrm{A}}}\right)^{1 / 2}\right]^{*} n_{p} }
\end{aligned}
$$

it follows that

$$
\begin{aligned}
n_{i}\left(\Omega_{\mathrm{A}}\right) & \leq \sum_{p}\left[\sum_{j}\left(\left\langle\phi_{j} \mid \phi_{j}\right\rangle_{\Omega_{\mathrm{A}}}\right)^{1 / 2} \tilde{U}_{j i}^{*} U_{j p}^{*}\right]\left[\sum_{k} \tilde{U}_{k i}^{*} U_{k p}^{*}\left(\left\langle\phi_{k} \mid \phi_{k}\right\rangle_{\Omega_{\mathrm{A}}}\right)^{1 / 2}\right]^{*} \\
& =\sum_{j}\left\langle\phi_{j} \mid \phi_{j}\right\rangle_{\Omega_{\mathrm{A}}} \tilde{U}_{j i}^{*} \tilde{U}_{j i} \leq \sum_{j} \tilde{U}_{j i}^{*} \tilde{U}_{j i}=1
\end{aligned}
$$

Thus,

$$
0 \leq n_{i}\left(\Omega_{\mathrm{A}}\right) \leq 1
$$

which proves eq 20.

\section{References and Notes}

(1) Bochicchio, R. C.; Torre A.; Lain L. J. Chem. Phys. 2005, 122, 084117.

(2) Alcoba, D. R.; Lain, L.; Torre A.; Bochicchio, R. C. J. Chem. Phys. 2005, 123, 144113

(3) Cioslowski, J.; Mixon, S. Inorg. Chem. 1993, 32, 3209.
(4) Cioslowski, J.; Mixon, S. J. Am. Chem. Soc. 1991, 113, 4142.

(5) Coleman, A. J. Rev. Mod. Phys. 1963, 35, 668.

(6) Cioslowski, J. Int. J. Quantum Chem. 1990, S24, 15.

(7) Foster, J. M.; Boys, S. F. Rev. Mod. Phys. 1960, 32, 300

(8) Edmiston, C.; Ruedenberg, K. J. Chem. Phys. 1965, 43, S97.

(9) Magnasco, V.; Perico, A. J. Chem. Phys. 1967, 47, 971.

(10) von Niessen, W. J. Chem. Phys. 1972, 56, 4290.

(11) Reed, A. E.; Weinhold, F. J. Chem. Phys. 1985, 83, 1736.

(12) Pipek, J.; Mezey, P. G. J. Chem. Phys. 1989, 90, 4916.

(13) Alcoba, D. R.; Lain, L.; Torre, A.; Bochicchio, R. C. J. Comput. Chem. 2006, 27, 596 .

(14) Cioslowski, J. J. Math. Chem. 1991, 8, 169.

(15) Bader, R. F. W. Atoms in Molecules: A Quantum Theory; Clarendon Press: Oxford, U.K., 1994; see also references therein.

(16) McWeeny, R. Rev. Mod. Phys. 1960, 32, 335.

(17) Alcoba, D. R.; Valdemoro, C. Int. J. Quantum Chem. 2005, 102, 629.

(18) Frisch, M. J.; Trucks, G. W.; Schlegel, H. B.; Scuseria, G. E.; Robb M. A.; Cheeseman, J. R.; Montgomery, J. A., Jr.; Vreven, T.; Kudin, K. N.; Burant, J. C.; Millam, J. M.; Iyengar, S. S.; Tomasi, J.; Barone, V.; Mennucci, B.; Cossi, M.; Scalmani, G.; Rega, N.; Petersson, G. A.; Nakatsuji, H.; Hada, M.; Ehara, M.; Toyota, K.; Fukuda, R.; Hasegawa, J.; Ishida, M.; Nakajima, T.; Honda, Y.; Kitao, O.; Nakai, H.; Klene, M.; Li, X.; Knox, J. E.; Hratchian, H. P.; Cross, J. B.; Bakken, V.; Adamo, C.; Jaramillo, J.; Gomperts, R.; Stratmann, R. E.; Yazyev, O.; Austin, A. J.; Cammi, R.; Pomelli, C.; Ochterski, J. W.; Ayala, P. Y.; Morokuma, K.; Voth, G. A.; Salvador, P.; Dannenberg, J. J.; Zakrzewski, V. G.; Dapprich, S.; Daniels, A. D.; Strain, M. C.; Farkas, O.; Malick, D. K.; Rabuck, A. D.; Raghavachari, K.; Foresman, J. B.; Ortiz, J. V.; Cui, Q.; Baboul, A. G.; Clifford, S.; Cioslowski, J.; Stefanov, B. B.; Liu, G.; Liashenko, A.; Piskorz, P.; Komaromi, I.; Martin, R. L.; Fox, D. J.; Keith, T.; Al-Laham, M. A.; Peng, C. Y.; Nanayakkara, A.; Challacombe, M.; Gill, P. M. W.; Johnson, B.; Chen, W.; Wong, M. W.; Gonzalez, C.; Pople, J. A. Gaussian 03, revision C.02; Gaussian, Inc.: Wallingford, CT, 2004.

(19) Mayer, I.; Salvador, P. Chem. Phys. Lett. 2004, 383, 368.

(20) Alcoba, D. R.; Lain, L.; Torre, A.; Bochicchio, R. C. Chem. Phys. Lett. 2005, 407, 379.

(21) Bochicchio, R. C.; Lain, L.; Torre, A. Chem. Phys. Lett. 2003, 374, 567.

(22) Biegler-König, F. W.; Bader, R. F. W.; Tang T. H. J. Comput. Chem. 1982, 3, 317.

(23) Shaik, S.; Danovich, D.; Silvi, B.; Lauvergnat, D. L.; Hiberty, P. C. Chem.-Eur. J. 2005, 11, 6358 . 